\title{
A imagem do pai em Lavoura ArCaica
}

\author{
por Fabiana Rached de Almeida-Abi ${ }^{1}$
}

\begin{abstract}
RESUMO: A intenção deste trabalho é discutir algumas das construções das imagens do pai e do filho, a partir do romance Lavoura Arcaica (1975), de Raduan Nassar, no filme homônimo LavourArcaica (2001), de Luiz Fernando Carvalho. Para tanto, valemo-nos de alguns conceitos da psicanálise de Freud e de Lacan a respeito da idéia de 'pai'. E, perpassando por alguns destes conceitos para o romance, tentamos entender como o desejo do filho se dá através do desejo do pai, constituindo-se esse desejo um elemento organizador da obra. Em outro aspecto, estudamos como as imagens do pai e do filho foram traduzidas no filme homônimo LavourArcaica (2001), de Luiz Fernando Carvalho, em determinados planos, por meio dos movimentos de câmera, numa espécie de edificação e destruição das personagens, e também como algumas imagens bíblicas podem ter sido inscritas no filme através de uma aproximação com uma pintura de Caravaggio. Nas duas obras, em algum momento, os sentidos em torno das relações parentais estabelecidas são tão trabalhados, bem escritos, posicionados com esmero ao longo dos dois discursos, que passam a ser extravasados e há um retorno à forma que subjaz o sagrado, à essência da idéia de autoridade, à estrutura da hierarquia em si.
\end{abstract}

PALAVRAS-CHAVE: Pai, Filho, Imagem.

ABSTRACT: the intention of this work is to argue some of the constructions of the images of the father and the son, from the romance To the left of the father (1975) of Raduan Nassar, in the homonym film (2001) of Luiz Fernando Carvalho. Some concepts of the psychoanalysis (Freud and Lacan) regarding the idea of "father" war using to stud romance; we try to understand as the desire of the son if of the one through the desire of the father, consisting this desire a important element. In another aspect, we study as that images had been translated the film homonym (2001) of Luiz Fernando Carvalho, in determined plain, by means of the movements of camera for construction and destruction of the personages and also as some Biblical images they can have been enrolled in the film through an approach with a painting of Caravaggio. At some moment, the directions in lathe of the established parental relations so are worked, written, "located well" with care throughout the two speeches, that pass to be limit and have a return to the "form" that subjaz the sacred one, the essence of the authority idea, the structure of the hierarchy in itself.

KEYWORDS: Father, Son, Image.

O romance Lavoura Arcaica pode ser lido como uma versão transgredida da parábola do filho pródigo. Com a mesma estrutura circular da parábola de base, o romance é divido em duas partes, uma primeira parte, mais extensa, intitulada $A$ partida, e uma segunda parte, intitulada $O$ retorno. Diferente do discurso bíblico, a narrativa se faz na primeira pessoa, sob o ponto de vista de André; há um movimento de retorno que percorre a narrativa tanto no sentido espacial (casa pensão; pensão - casa) como no sentido temporal. André acorda recordações misturadas no tempo e no espaço, desordenadas do ponto de vista seqüencial, como se os relatos fossem concatenados por um processo de livre associação. Esse processo começa com a visita de Pedro, o irmão mais velho, que tem como missão devolver o filho pródigo a casa da família. A presença de Pedro suscita uma série de recordações que seguem desde as tardes da infância num esconderijo do bosque da fazenda, de volta à pensão, passando pela lembrança da mãe (dos olhos

\footnotetext{
${ }^{1}$ Mestranda da Universidade Estadual de Campinas (Unicamp - São Paulo), Brasil, e bolsista CNPq. Contato: almeida.abi@hotmail.com
} 
da mãe)e pela casa da família, até o momento em que André revela seu amor pela irmã, Ana, e conseqüentemente a consumação do incesto, relatado no final da primeira parte do romance. A narrativa percorre esse ziguezague, colocando o leitor ora como acompanhante do processo de recordação, ora no lugar de Pedro que toma conhecimento dos fatos até então ignorados, que implicam situações de transgressão em relação à palavra do pai.

De acordo com Freud, em Totem e Tabu (1913), houve um tempo em que o homem primitivo vivia em pequenas tribos, governado por um macho forte que exercia a função de senhor e pai do grupo ao mesmo tempo. O poder desse senhor era irrestrito e o destino dos filhos era inseguro sob seu comando. Caso despertassem ciúmes no pai seriam mortos, expulsos ou castrados. Se fugissem, teriam que raptar mulheres tomando-as como esposas e talvez se tornarem senhores como o pai. Porém, em algum momento, os irmãos expulsos unidos se revoltaram contra a onipotência do pai. E, após matá-lo, como era de costume, devoraram-no cru. Depois disso, os irmãos começaram a se enfrentar por causa da herança, o lugar do pai. Daí surgiu o primeiro contrato social baseado numa aliança fraterna, pois os filhos descobriram que teriam que renunciar ao instinto em função de outros valores que legislavam a preservação da espécie.

Após a matança, nasce o sentimento de culpa nos filhos. E é através da adoração do Totem que os filhos se reconciliam com o pai morto. Assim, surge a religião totêmica como forma de expurgar o crime parricida. E, só depois de um tempo, o assassinato é proibido e formulado como um mandamento: "não matarás". No entanto, para Freud, a rebeldia vem à tona a cada nascimento humano e as lutas para infringir as leis são constantemente efetuadas. Assim, estariam postas as duas hipóteses sobre a gênese da cultura: a do Édipo universal e a do parricídio original.

Valendo-se ainda de uma análise empreendida nas tribos australianas, africanas, indianas e outras, Freud constatou que o horror ao incesto não teria surgido das necessidades religiosas do homem, mas, sim, das necessidades cotidianas e práticas.

É através deste relato que Freud formula a famosa triangulação edípica: o filho que deseja o genitor do sexo oposto e sente como rival o genitor do mesmo sexo. Assim, inicia a discussão dos dois tabus que deram origem à moralidade humana. Uniu o mito de Édipo ao mito da horda primitiva. Num primeiro momento, sua tentativa foi de encontrar vestígios primitivos do totemismo na infância do indivíduo como se a criança fosse uma espécie de homem primata. Dessa forma, o homem atravessaria a revolta dos filhos contra o pai tirânico. Não haveria civilização sem a renúncia instituída pela lei. A família seria a herdeira direta da estrutura do Totem. E, através do complexo de Édipo, cada um de seus membros sofreria duplamente, pois a herança filogenética estaria impressa na memória de cada sujeito. O ancestral do pai da família moderna seria o totem dos membros do clã primitivo.

Segundo Roudinesco, "como essa história de banquete totêmico tinha o aspecto de uma extrapolação fantasística" (1994, p.216), ela foi contestada no começo dos anos 20 pelos antropólogos anglo-saxões. Para eles, os argumentos de Freud eram fracos, visto que estavam apoiados no pressuposto de uma origem única de toda cultura e presumiam que esta fosse idêntica para todas as sociedades. A antropologia já havia ultrapassado esse evolucionismo do qual Freud permanecia tributário.

As idéias de Freud foram rebatidas mais tarde e só retornariam de forma sensata com Lévi-Strauss, nos anos 40, que demonstrou a relevância da proibição do incesto nas sociedades e viu que a interdição do incesto era responsável pela passagem da natureza à cultura. Em Estruturas Elementares do Parentesco (1973), ele confronta o arcabouço psicanalítico ao 
substituir a família pelo parentesco e, principalmente, ao colocar que a proibição de certos encontros era ligada à existência de uma função simbólica, uma espécie de lei organizada pela sociedade. A interdição seria uma instituição social.

Lacan, obviamente já consciente dos estudos de Lévi-Strauss, retorna a Freud postulando o triângulo edípico como uma função simbólica, isto é, como uma lei que organiza o inconsciente da civilização: "se Freud coloca no centro de sua doutrina o mito do pai, é claro que é em razão da inevitabilidade da questão" (LACAN, 2005, p.71). No entanto, para ele, Freud encontra um equilíbrio "desejável" no mito, o da Lei e do desejo. Já Lacan fala do mito em três termos: gozo, desejo e objeto, pois a conformidade entre a Lei e o desejo, dentro da lei do incesto, só pode nascer do gozo do pai primordial.

O pai primitivo, "ancestral", só poderia estar no âmbito do mito:

o pai só pode ser um animal, o pai primordial é anterior ao interdito, anterior ao surgimento da Lei, da ordem das estruturas da aliança e do parentesco, em suma, anterior ao surgimento da cultura. Eis porque Freud fez dele o chefe da horda, cuja satisfação, de acordo com o mito animal é irrefreável. (LACAN, 2005, p.73)

Aproximando-se da antropologia, da lingüística de Saussure, Lacan passa a tratar esse problema fundamental como "estrutura de linguagem". O enigma de Édipo passa a ser encarado como um universal simbólico em detrimento do universal natural de Freud.

$\mathrm{Na}$ verdade, o que se herdaria de uma geração a outra seria a estrutura significante. E ainda, não era mais possível ver a relação edípica como um triângulo: pai, mãe e filho. Era preciso entender essa estrutura a partir de um quarto elemento: o falo, que seria a simbolização de uma relação, na qual o órgão sexual masculino seria um elemento parcial dentro dessa estrutura significante.

O Édipo, enquanto mito, deveria ser retomado simbolicamente ${ }^{2}$. Segundo Lacan, a formação imaginária organizará o drama vivido por todo sujeito. Mas, mesmo sendo imaginárias, essas fantasias acabam por ser organizadas pelo registro simbólico. Dessa forma, as ações referentes a este primeiro triângulo amoroso ficam em torno da metáfora paterna, o Nome-do-Pai. E essa metáfora servirá como base da trajetória do Édipo humano.

Se o sujeito é subjugado pela linguagem, a função do pai é também inconcebível sem a categoria do significante ${ }^{3}$ : "é necessário colocar no nível do pai um segundo termo depois do totem" (LACAN, 2005, p.73). Ao nomear o filho e lhe dar um sobrenome, o pai intervém em seu narcisismo; interfere no amor absoluto entre mãe e filho.

O pai, ao nomear seu filho, marca-o socialmente e o circunscreve no grupo a que pertence. O nome do pai é de alguma forma o não do pai, porque, ao mesmo tempo em que

\footnotetext{
${ }^{2}$ Dentro do ternário lacaniano, RSI (real, simbólico e imaginário), o pai é definido em três esferas: pai imaginário, pai real e pai simbólico. Os dois primeiros são os agentes de operações como, respectivamente, privação e castração. O pai simbólico não é agente de uma operação; ele é a elevação da palavra do pai à esfera do significante. O pai simbólico é representado pelo pai morto, ou melhor, o pai assassinado: "tué". De acordo com Erik Porge: "Desse modo ele é conservado, segundo a indicação da etimologia comum, tueri. Tuer [matar, assassinar] vem de tutare, proteger, guardar. É o freqüentativo de tueri, resguardar, proteger, defender, matar, extinguir o fogo; o fogo é um ser vivo, e matá-lo é mitigá-lo" (PORGE, p.139).

${ }^{3}$ O pai não é só o genitor, mas uma função que depende do modo como o indivíduo assume o significante na linguagem, simbolizando essa relação parental.
} 
integra, delimita os acessos de realização dos desejos. O pai introduz o filho na esfera social; sua presença convoca o mundo exterior e suas leis.

Para Lacan (2005), o nome é uma marca aberta à leitura. Não é à toa que o nome será lido da mesma forma em todas as línguas; é uma impressão sobre algo que pode ser um sujeito que fala, "mas que não falará de modo algum obrigatoriamente" (LACAN, 2005, p.74). É como as marcas de um alfabeto semita numa antiga cerâmica: a cerâmica não poderia tomar a palavra para responder que aquela é sua marca de fábrica. O nome está situado nesse nível.

Na tradição judaico-cristã, o nome de Deus é o Nome (Shem). Deus é aquele que é: "eu sou aquele que sou" - ele (Eloim) fala para Moisés na sarça ardente, Êxodo. Para Lacan (2005), o que marca o misticismo dessa tradição é a incidência do desejo de Deus, que se faz pivô.

Em Lavoura Arcaica (1975), é o próprio pai que mata a filha, marcando a interdição do incesto. O pai, para manter seu poder, sacrifica a filha e assim ele castra a si mesmo e o filho, André. Poderíamos pensar que o pai também se sente tentado por ela e sua morte é a recomposição da ordem primitiva. Ana representa uma ameaça ao clã. Há um deslocamento da mãe para a irmã. A mãe seria a genitora do sexo oposto, pela qual o filho sente desejo e é interditado pelo pai.

Para Freud, o incesto conjugaria a Lei e o desejo e representaria, assim, o gozo puro do pai como autoridade primordial. Isso daria a marca da formação do desejo na criança em seu processo de formação normal. Para Lacan, este é o momento gerador das neuroses. A neurose é antes uma fuga diante do desejo do Pai que o sujeito substitui por sua demanda. Há uma ligação estreita entre a função da perversão e sua relação com o desejo do Outro como tal. A perversão poria "contra a parede a apreensão ao pé da letra da função do pai, do Ser Supremo" (LACAN, 2005 , p. 75). Dessa forma, o desejo dito normal se coloca no mesmo patamar do desejo dito perverso e a incidência disso é um grande leque que vai da neurose ao misticismo, compreendidos dentro de um todo.

Por isso não é tão distante afirmarmos que o pai, Iohaná, deseja Ana, sua filha. André, na verdade, deseja o desejo do Pai. Ele não supera esta condição de desejar o que é do pai. O pai, por sua vez, traça outro percurso em relação ao seu próprio pai, o avô. Se o avô era lacônico, o pai é palavroso e sua superação se dá pelas vias do misticismo, usando da manifestação de ou dos apelos a Deus para substituir o desejo do pai.

Mas, de certa forma, a memória do filho desautoriza o pai, revelando a contradição de seus discursos e denunciando o ancestral, num misto de cólera e culpa. Não temos notícia sobre se há superação deste pai. Em Lavoura Arcaica (1975), o romance familiar é retomado à custa da dor, da culpa e do gozo próprio da infância e não da superação. O discurso final é o discurso do pai. A superação não se dá pela morte da irmã como suposta interdição do incesto e nem pela morte do pai, marcando o fim de sua violência para com os filhos e a posse de seu 'lugar' pelo filho.

Freud diz que a herança do pai deve ser conquistada. E, para tanto, é preciso, dentre outras coisas, deixar a casa da família:

ao crescer, o indivíduo liberta-se da autoridade dos pais, o que constitui um dos mais necessários, ainda que mais dolorosos, resultados do curso do seu desenvolvimento. Tal liberação é primordial e presume-se que todos os que atingiram a normalidade lograram-na pelo menos em parte. Na verdade, todo o progresso da sociedade repousa sobre a oposição entre as gerações sucessivas. 
Existe, porém, uma classe de neuróticos cuja condição é determinada visivelmente por terem falhado nessa tarefa. (FREUD, 1906-1908, p.219)

André não só deixa a casa paterna como a subverte, mas mesmo assim não há superação. Ele quer o lugar do pai. No retorno do filho a casa, André diz a Iohána: "queria o meu lugar na mesa da família”. (NASSAR, 2002, p.160). A mesa da família é o lugar onde os sermões são proferidos, lugar da palavra do pai.

Como ele poderia ser feliz longe dali se seu desejo corresponde ao amor da família? Ele deseja se religar ao clã. André só se redime enquanto filho arredio se tiver o amor da irmã:

foi um milagre, querida irmã, descobrirmos que somos tão conformes em nossos corpos, e que vamos com nossa união continuar a infância comum, sem mágoa para nossos brinquedos, sem corte em nossas memórias, sem trauma para nossa história; foi um milagre descobrirmos acima de tudo que nos bastamos dentro dos limites da nossa própria casa, confirmando a palavra do pai de que a felicidade só pode ser encontrada no seio da família; foi um milagre, querida irmã, e eu não vou permitir que este arranjo do destino se desencante, pois eu quero ser feliz, eu, o filho torto, a ovelha negra que ninguém confessa, o vagabundo irremediável da família, mas que ama nossa casa, e ama esta terra, e ama também o trabalho, ao contrário do que se pensa... (NASSAR, 2002, p.120121)

Foi esse o amor que ele provou na infância; foi a família que ele aprendeu a amar. É possível dizer que André acredita nisso. A dor vem da impossibilidade de continuar ligado à família. Mesmo que ele abandone a casa, ele não supera o desejo (que depois se transformará em dor, uma vez que ele verá a impossibilidade de satisfazê-lo) genuinamente cultivado na infância. André foi traído, o amor na família pode ser traiçoeiro; mas, ele não aceita e não supera. $O$ pai morto não o autoriza; desdizê-lo não macula a imagem do patriarca. Nem amá-lo, nem odiá-lo representam formas de superá-lo.

A superação, se há, é pela linguagem - pela confissão, pela catarse —, pela criação artística. Há um trabalho intenso com a linguagem como para se depurar um verbo original, descarnado do verbo ancestral. Pela reiteração do verbo paterno dentro de uma língua já autorizada / possuída pelo filho. A superação se dá pelo significante, pelo gozo do significante, pela inversão na estrutura. Ou seja, há um retorno às origens (uma releitura da parábola, por exemplo) para que se possa recontar o mito. Não propriamente nos fatos, nas consequiências. Mas, na retomada através do simbólico; no desvelamento das neuroses.

No filme, tais processos ocorrem pela recuperação de trechos fundamentais da literatura vertidos em closes, enquadramentos, movimentos de câmera e pela reconstrução de figuras bíblicas tomadas por um jogo de claro e escuro como nas obras de Caravaggio, que captam esse velar (sombra) e desvelar (iluminação) lingüísticos.

A obra fílmica traduz as imagens do pai, do avô e do filho de diferentes formas. As imagens do pai são geralmente captadas por um movimento de câmera panorâmica oblíquo (de baixo para cima), dando dimensão à imagem, como se olhássemos para o dorso de uma estátua - tal qual o Totem, uma imagem carregada de ódio, afeto e admiração; ele é insuperável, é o animal primordial. Os closes privilegiam sua cabeça e não há câmera subjetiva que transmita a idéia de um olhar seu para a história, como acontece com as outras personagens.

A imagem do pai aparece no filme pela primeira vez aos 12:37 - 12:39 (duração do plano até o corte seguinte) e é acompanhado de uma canção árabe (imagem sonora — voz canta 
em árabe). A câmera sobe (movimento de câmera panorâmica inclinada) mostrando o tronco do homem - de baixo para cima - , sendo que este homem deve ser visto em sua grandeza. Um homem barbado, de coletes escuros, camisa de manga longa, ao seu lado um lampião. Ele parece sentado, na ponta de uma mesa, tal qual um chefe. O lampião ao lado é a luz, a clarividência, a sabedoria. Ele lerá algo? Depois do corte, a voz do narrador em off esclarece a cena: os filhos a sua volta do lado direito fazem parte do tronco firme da casa e do lado esquerdo, a mãe e sua extensão: Pedro, Ana e Lula, o caçula. Outras sequiências do pai na mesa serão retomadas mais para frente. A priori, capta-se o trecho:

\begin{abstract}
e o pai à cabeceira fez a pausa de costume, curta, densa, para que medíssemos em silêncio a majestade rústica de sua postura: o peito de madeira debaixo do algodão grosso e limpo, o pescoço sólido sustentando uma cabeça grave, e as mãos de dorso largo prendendo firmes a quina da mesa como se prendessem a barra de um púlpito; e aproximando depois o bico de luz que deitava um lastro cobre mais intenso em sua testa, e abrindo com os dedos maciços a velha brochura, onde ele, numa caligrafia grande, angulosa, dura trazia textos compilados, o pai ao ler não perdia nunca a solenidade: 'Era uma vez um faminto'. (NASSAR, 2002, p.62)
\end{abstract}

É possível aproximar a imagem deste pai do quadro $O$ sacrifício de Isaac de Caravaggio com a figura de Abraão, por exemplo. A iluminação preponderante no topo da cabeça, nas mãos. O tronco mais proeminente que o resto do corpo, as barbas fartas. O pai como os líderes bíblicos, como Abraão, é dado à austeridade, à cólera, à defesa do clã, à perpetuação da palavra do Pai. Abraão foi um dos primeiros dos patriarcas de Israel, chefe de um clã arameu, na Caldéia, que emigrou para Canaã. Uma das figuras mais importantes das religiões judaica, islâmica e cristã, pois representa para todas elas a transição da idolatria para a crença em um só Deus. Depois que sua família se mudou para o norte, ele recebeu uma revelação para deixar o país para seguir uma orientação divina. Com a esposa Sara, Abraão dirigiu-se a Canaã, a região indicada por Deus. Sara era estéril e, em obediência às leis da época, entregou a Abraão sua escrava Agar, que dele concebeu e deu à luz Ismael. Os descendentes de Ismael viriam a ser os árabes.

A figura do pai em LavourArcaica pode se assemelhar a figura mitológica de Abraão. O pai também é um imigrante árabe e tem como incumbência manter a obediência do clã e proferir a palavra do pai (seja da cultura, seja divina). O pai sustenta o discurso bíblico. É ele que, por meio de parábolas (sempre consultadas nos livros), assume o discurso cristão e seus imperativos, Iohána se coloca como pregador nos sermões à mesa das refeições.

De qualquer forma, no filme reveste-se de elementos universais a figura do pai da literatura, para que ele assim também tenha a magnitude da estátua, a magnitude da ação do mito (lembrando que no filme a imagem é uma imagem-ação / imagem-tempo).

$\mathrm{Se}$, no romance, a superação se dá pelo significante que, dentre outras coisas, recupera a estrutura para subvertê-la; no filme, isso ocorre pela recuperação da forma pela tentativa de preenchimento da Gestalt através de um delineamento barroco próprio desses quadros cristãos. 


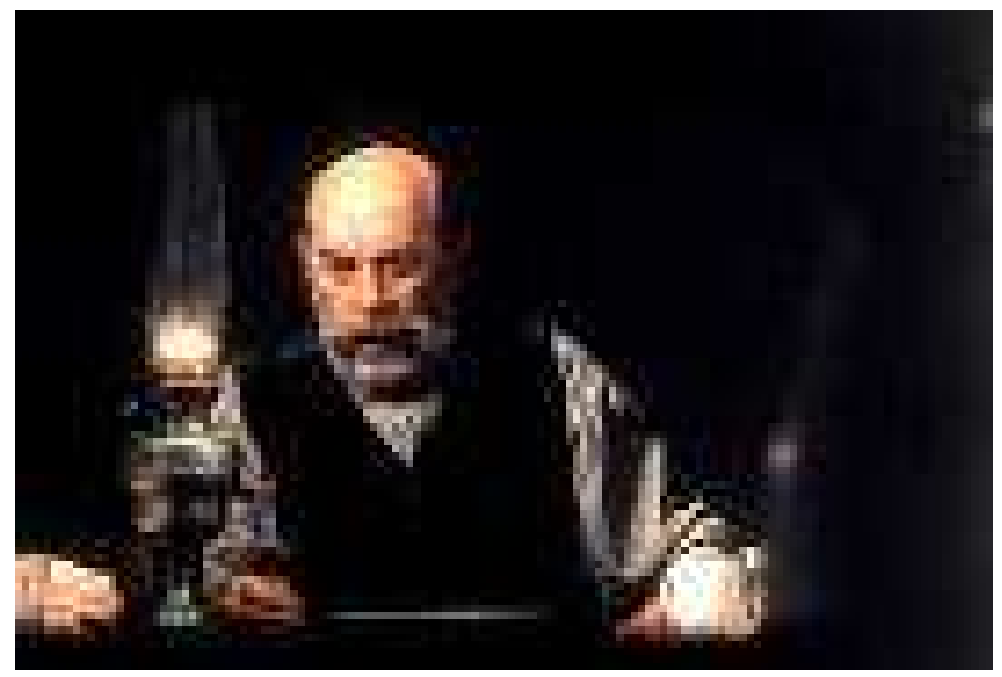

Figura I: o pai na mesa dos sermões (LAVOURARCAICA, 2001)

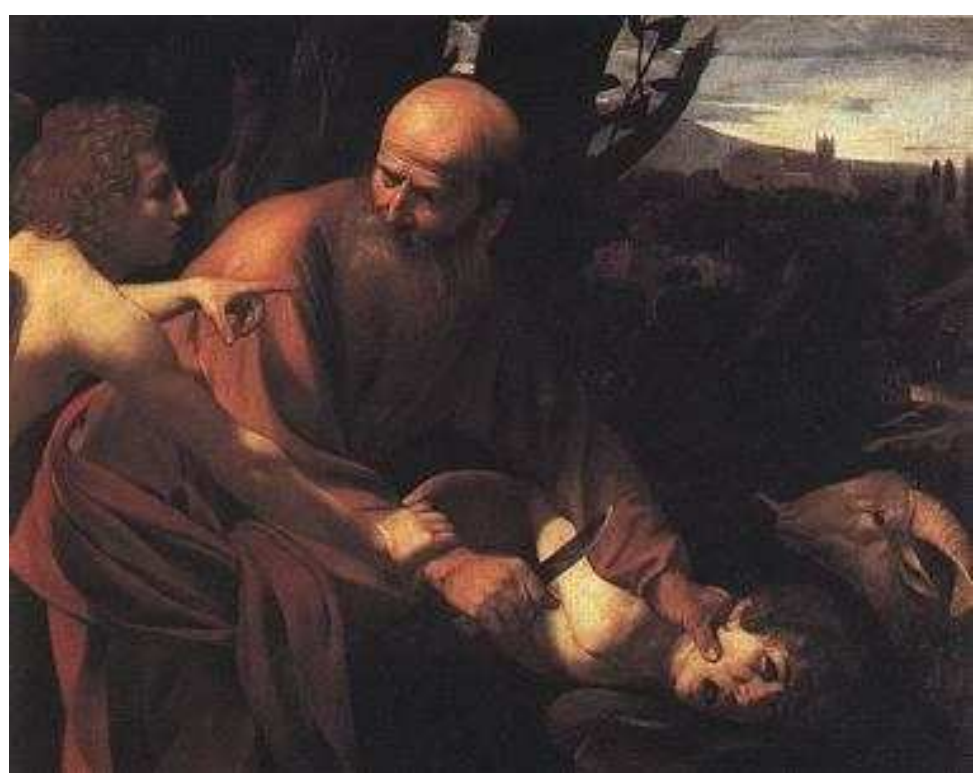

Figura II: O sacrifício de Isaac (CARAVAGGIO, 1603)

Essa obra de Caravaggio representa Abraão sacrificando seu filho, Isaac, ao Eloim. Quando Abraão e Sara já eram anciãos, nasceu-lhes Isaac, o herdeiro das promessas divinas. Deus pôs à prova a fé do patriarca ordenando-lhe que sacrificasse Isaac, e ele obedeceu prontamente. Um anjo, no entanto, deteve a mão de Abraão e substituiu o menino por um cordeiro. Deus prometeu a Abraão uma descendência que se multiplicaria como as estrelas do céu e como a areia que está na beira do mar. Abraão representa a origem de um povo eleito por Deus para renovar a humanidade, mas também o homem justo, profundamente fiel, cuja lealdade a Deus chegaria ao ponto de sacrificar o filho em obediência à ordem divina.

Para Lacan, essas imagens do sacrifício de Isaac pintadas por Caravaggio recuperam a metáfora paterna. Não que os "Nomes" estejam aí representados, mas tudo que há na metáfora paterna aí se encontra. Nessa obra de Caravaggio, por exemplo, o anjo é a presença "daquele cujo Nome não é pronunciado" (LACAN, 2005, p.80). Ele é enviado por El Shadaaí. El Shadaaí é 
aquele que elege; que promete e que se faz passar por uma única aliança que é transmissível apenas pela "baraka paterna" (LACAN, 2005, p.82).

O cordeiro seria o animal primordial e ele estava ali, segundo a tradição rabínica, desde os sete dias da criação; ele representa não só aquele cujo nome é impronunciável, mas todos os Eloim. O cordeiro é reconhecido como o ancestral da raça de Sem, aquele que se junta a Abraão nas origens. E esse é o animal que é designado para ser sacrificado no lugar de Isaac. Esse cordeiro é o Deus de sua raça:

\begin{abstract}
marca-se aqui o gume da faca entre o gozo de Deus e o que, nessa tradição, presentifica-se como seu desejo. Aquilo de que se trata de provocar a queda é a origem biológica. Aí está a chave do mistério, em que se lê a aversão da tradição judaica a respeito do que existe por outro lado. $\mathrm{O}$ hebraico odeia a prática dos ritos metafísicos-sexuais que, na festa, unem a comunidade ao gozo de Deus. Valoriza, ao contrário, a hiância que separa desejo e gozo." (LACAN, 2005, p. $85)$.
\end{abstract}

Essa hiância pode ser encontrada na relação de Abraão com o Deus. E é a partir daí que nasce a lei da circuncisão. O pedaço de carne cortada é o sinal da aliança do povo com aquele que o elegeu.

Em Lavoura Arcaica, a morte de Ana soa como um sacrifício. O pai, para manter o clã e seu poder, não pode permitir a relação entre os irmãos. Ana é uma das mulheres do pai, um dos "nãos" do pai. E, Ana, também por ser mulher, é sacrificada. Ana é uma espécie de animal primordial; ela tem a singeleza, a pureza do branco, do natural, do sagrado (talvez esta seja a figura de maior representação do sagrado na obra). Ana é apenas presença, movimento. O nome Ana em hebraico é Hannah que vem a ser "a graça de Deus". A letra A é o um número 1; 'a' é a primeira vogal e a primeira letra do alfabeto. Ana representa as origens - a união com a irmã é um encontrar-se consigo mesmo. Ana em árabe significa 'eu' , antes da cisão feita pela cultura. Luiz Fernando Carvalho, numa espécie de "jogo de junção fônica com as palavras", designa sua leitura da obra literária pelo nome: LavourArcaica, iniciando sua tradução sob o signo 'A' , que representa início, e, nesse caso, recriação, recomeço. A criação e a recriação têm sua matriz em $A$ como Ana é a fonte de amor e criação e na obra. Ana pode representar 'matriz' e 'matriz', por reflexo, retorna a mãe. Mas, a mãe talvez pela idade não possa mais gerar filhos, gestar criação, legando a tarefa para a filha.

O pai circuncida André através da morte de Ana. Ana não fala, ela é apenas lugar que se torna lugar de possessão. No fim, ela é sacrificada. Matar Ana é matar o amor e a união. Agora, o lugar é vago. Desgraçados os homens a partir de agora, pois haverá uma luta pelo poder - lugar do pai. Mas, o pai assassina a própria descendência com a morte de Ana. Ana é ao mesmo tempo a cisão pessoal e mitológica.

A inovação da obra de Nassar está justamente em colocar o elemento que faria parte do pecado na esfera do sagrado. O pai poderia sacrificar seu filho, como Abraão faria com seu filho Isaac. Mas o pai 'poupa' o filho homem e mata sua filha, privando todos daquilo que seria o puro e o verdadeiro, o original. A imagem de Ana é, em algum momento, também a imagem da salvação. O pai, extinguindo a própria fillha, também se extingue.

A última imagem do pai no filme simboliza a morte, o homem com um alfanje que será desferido contra a própria filha. A morte de Ana é metonímica, o cravo vermelho que ela porta cai no chão como um coalho de sangue. O tronco do pai, que é emoldurado pela câmera de baixo para cima, cai. Ele é visto de cima para baixo, como uma estátua que foi tombada. 
Na literatura, a morte de Ana é sonorizada pelos gritos da família:

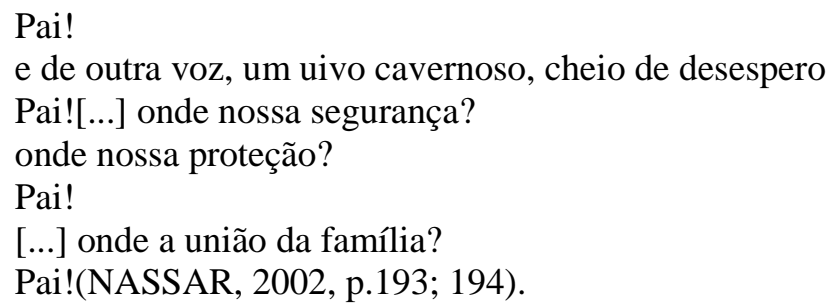

Os gritos da família podem ser vistos como uma espécie de oração, talvez, uma oração invertida que coloca em questão a figura protetora do pai. Mas, não só o pai desse romance, e, sim, a figura do Deus, o pai supremo. Afinal, se pensarmos na história da narrativa como um todo, veremos que há um desamparo de todas as personagens perante a vida. $\mathrm{O}$ pai não deixa de ser uma vítima da situação criada, talvez, pelo medo, pela fé e pela manutenção da proteção, da segurança e perpetuação daquele clã. O pai também é uma vítima da carga explosiva que há em sua própria "palavra semente". Também vítima do "musgo dos textos dos mais antigos" e da interpretação que todos nós podemos fazer deles.

No filme, é a voz em off do pai que finaliza a narração fílmica. Essa imagem sonora é acompanhada da imagem de André cobrindo-se com folhas secas numa espécie de enterro. A voz do pai e a música As costas do tempo (faixa 21 da trilha sonora) compõem o réquiem desse enterro. A voz em off já sinaliza que esse pai não está mais ali. É a voz de um morto. Sem que seja dito, aparece implícito na fala do pai: "em memória de meu pai", como é dedicado, na literatura, o último capítulo.

As imagens de André são às vezes fragmentadas, despedaçadas (pedaços do corpo) ou então o corpo é tomado pela experiência, pela tentativa de tradução das experiências. O corpo despedaçado está relacionado ao gozo (corpo pulsante) e ao sofrimento, porque o desmembramento está relacionado à interdição, ao não do pai. O pai não se desmembra, é uma figura única, o dorso de uma estátua. Mas André se faz e desfaz. Se o pai é a Gestalt, a forma, o filho é o corpo pulsante, que deseja uma forma, mas incapaz de se ver inteiro; ele é inacabado e interrompido. O desejo pela irmã o liberta e o corrói porque é impossível ser vivenciado. Ele procura, a despeito da racionalização do pai e de seu afastamento / negação das pulsões, religarse ao clã.

Se as relações entre pai e filho e o incesto entre os irmãos são revestidos por outros textos como numa espécie de tentativa de se depurar um verbo original tal qual um texto-tecido, voltando-se, assim, à 'forma' que seria o triângulo edípico e conseqüentemente a estrutura da hierarquia e da dominação. No filme, isso pode ser depurado por construções de imagens que retomam um imaginário cristão, compostos, por exemplo, pela obra barroca de Caravaggio. Talvez, o filme consiga traduzir com imagens 'sagradas' — que remetem ao sagrado - a sensação da interrupção / castração da lei do pai. No romance, é o sagrado que está velado, que será sentido. No filme, são as imagens bíblicas que remetem ao totem uma vez que o espectador contemporâneo pode vislumbrar as origens, as leis, nos mitos cristãos. Jean Claude Bernardet (1995), ao analisar aspectos da obra de Zé Celso e Vilela pontua que o difícil na obra de arte hoje é reinstalar o sagrado. O teatro como lugar da profanação, principalmente dos valores cristãos, é algo muito explorado, mas é preciso muito empenho para recriar os mistérios do sagrado; muito empenho para provocar a angústia que ele instala na obra, provocando não a banalização ou o repúdio no espectador, mas a experiência reveladora, própria do sublime. E Luiz Fernando 
Carvalho consegue emoldurar esse aspecto da obra de Raduan Nassar. A idéia de reproduzir a 'forma' é tangenciar o sagrado, a partir de uma necessidade constante de retomá-lo e superá-lo. $\mathbf{d}^{\mathbf{g}}$

\section{REFERÊNCIAS BIBLIOGRÁFICAS:}

AUMONT, J. A Imagem. Tradução: Estela dos Santos, Cláudio César Santoro. Campinas: Papirus, 1993.

BÍBLIA SAGRADA. Tradução de João Ferreira de Almeida. Brasília: Sociedade bíblica no Brasil, 1969.

CADERNOS DE LITERATURA BRASILEIRA, n.2. Raduan Nassar. São Paulo: Instituto Moreira Salles, 1996.

CARVALHO, L. F. Sobre o filme LavourArcaica. São Paulo: Ateliê Editorial, 2002.

FREUD, Sigmund. Obras completas (vol. VI/ 1983 - 1899). Tradução: Jayme Salomão. Rio de Janeiro: Imago, 1996.

. (1996). Obras completas (Volume IX / 1906 - 1908). Tradução: Jayme Salomão. Rio de Janeiro: Imago, 1996.

. Obras completas (Volume XIII / 1913 - 1914). Tradução: Jayme Salomão. Rio de Janeiro: Imago, 1996.

LAVOURarcaica. Direção de Luiz Fernando Carvalho. Produção Donald K. Ranvaud e Luiz Fernando Carvalho. Adaptação do romance homônimo de Raduan Nassar. 2001. Rio de Janeiro: Riofilme distribuidora, 2001. 1 bobina cinematográfica (163 min), son., color., $35 \mathrm{~mm}$.

LACAN, J. Escritos. Tradução: Vera Ribeiro. Jorge Zahar: Rio de Janeiro, 1998. . Os Nomes-do-Pai. Tradução: André Telles. Jorge Zahar: Rio de Janeiro, 2005.

NASSAR, R. Lavoura Arcaica. São Paulo: Companhia das Letras, 2000.

PORGE, E. Jacques Lacan, um psicanalista - percurso de um ensino. Tradução: Nina Leite. Editora UNB, Brasília, 2006.

ROUDINESCO, E. Jacques Lacan, esboço de uma vida, história de um sistema de pensamento. Tradução: Paulo Neves. Companhia das Letras, São Paulo, 1994.

SEDLMAYER, S. Ao lado esquerdo do pai: os lugares do sujeito em Lavoura Arcaica, de Raduan Nassar. Tese (Mestrado em Literatura Brasileira) - Universidade Federal de Minas Gerais, Belo Horizonte, 1995. 